\title{
Comparative analysis of internal and external- hex crown connection systems - a finite element study
}

\author{
Rudi C. Van Staden ${ }^{*}{ }^{1}$, Hong Guan ${ }^{1}$, Yew-Chaye Loo ${ }^{1}$, Newell W. Johnson ${ }^{1} \&$ Meredith Nell $^{2}$ \\ ${ }^{1}$ Griffith School of Engineering/Dentistry and Oral Health, Griffith University, Gold Coast Campus, Queensland 4222, Australia. ${ }^{2}$ Neoss Pty \\ Ltd,Harrogate HG1 2PW, United Kingdom.*Correspondence should be addressed to RudiC. Van Staden (r.vanstaden@griffith.edu.au).
}

\begin{abstract}
Objectives: The abutment connection with the crown is fundamental to the structural stability of the implant system and to the prevention of mechanical exertion that can compromise the success of the implant treatment. The aim of this study is to clarify the difference in the stress distribution patterns between implants with internal and external-hex connections with the crown using the Finite Element Method(FEM). Materialand Methods: The internal and external-hex connections of the Neoss and $3 i$ implantsystems respectively, are considered. The geometrical properties of the implant systems are modeled using threedimensional (3D) brick elements. Loading conditions include a masticatory force of 200,500 and $1000 \mathrm{~N}$ applied to the occlusal surface of the crownalong with an abutmentscrew torque of 110,320 and $550 \mathrm{Nmm}$. The von Mises stress distribution in the crown is examined for all loading conditions. Assumptions made in the modeling include: 1 . half of the implant system is modeled and symmetrical boundary conditions applied; 2 . temperature sensitive elements are used to replicate the torque within the abutment screw. Results: The connection type strongly influences the resulting stress characteristics within the crown. The magnitude of stress produced by the internal-hex implant system is generally lower than that of the external-hex system. The internal-hex system held an advantage by including the use of an abutment between the abutment screw and the crown. Conclusions: The geometrical design of the external-hex system tends to induce stress concentrations in the crown at a distance of $2.89 \mathrm{~mm}$ from the apex. At this location the torque applied to the abutment screw also affects the stresses, so that the compressive stresses on the right hand side of the crown are increased. The internal-hex system
\end{abstract}

has reduced stress concentrations in the crown. However, because the torque is transferred through the abutment screw to the abutment contact, changing the torque has greater effect on this hex system than the masticatory force. Overall the masticatory force is more influential on the stress within the crown for the external-hex system and the torque is more influential on the internal-hexsystem.

Keywords: Component; Biomedical modelling; Dental implant; Finite element technique

\section{INTRODUCTION}

Dental implants are a consistently accepted form of dental treatment. Clinical research in oral implantology has led to advancements in the biom echan ical as pects of implants, implant surface features and implant componentry. These advancements in implant componentry include the modification of the external-hex connection between the abutment and crown to the currently used internal-hex (Figure 1b)). Although both internal and external-hex connected implant systems are extensively used, distinctly different performances are on offer in terms of the stress characteristics produced within the crown. Observations by practitioners have aided the identification of implant components which lead to mechanical failure of the crown and implant [1-3]. Failure may be defined as the point at which the material exceeds the fracture stress, as indicated by its stress strain relationship. There are two major factors which can cause the crown and implant to fail. These are described below;

- typically, over tightening of the abutment screw causes failure of the crown for internal and externalhex systems.

- failure of the implant may also be a result of over tightening of the abutment screw or excessive masticatory loads being transferred from the occlusal plane of the crown to an area of stress concentration at the interface between the abutment and implant body. 
Using theoretical techniques, such as the FEM, all mechanical aspects that could affect the implant success can be evaluated. FEM has been used extensively to evaluate the performance of dental implant prosthesis [4-15]. Studies by Maeda et al. (2006), Merz et al. (2000) and Khraisat et al. (2002) have all considered the behavior of the stress within the abutment screw however disregarding the stress within the crown. To date no published research appears to have investigated the stress characteristics in the crown due to an internal or external-hex system. Ultimately, the outcome of this study will facilitate dental practitioners to identify locations within the implant system that are susceptible to stress concentrations.

\section{METHODOLOGY}

The modeling and simulation herein are performed using the Strand7 Finite Element Analysis (FEA) System (2004). The first step of the modeling is to define the geometry of the implant system. This is then followed by specifying the material behavior in terms of the Young's modulus, Poisson's ratio and density for the implant and componentry. After applying the appropriate loading and restraint conditions, the

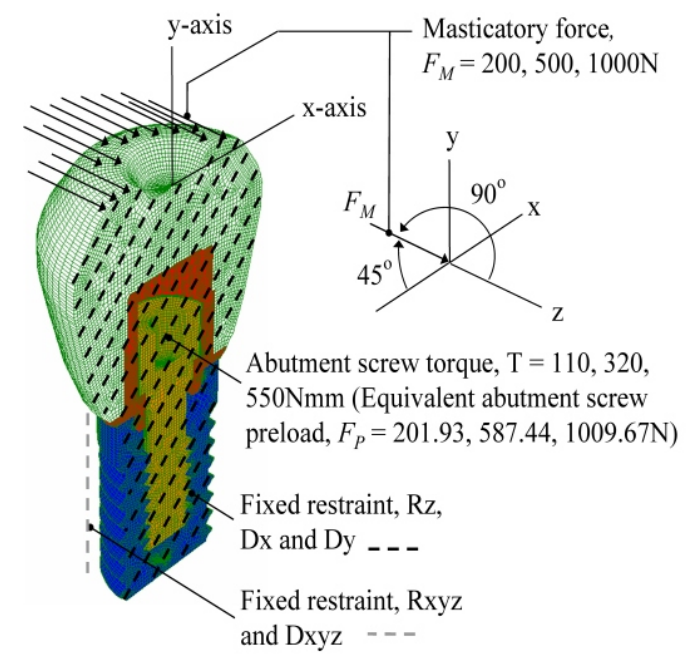

a) Loading and restraint conditions (with detailed variables)

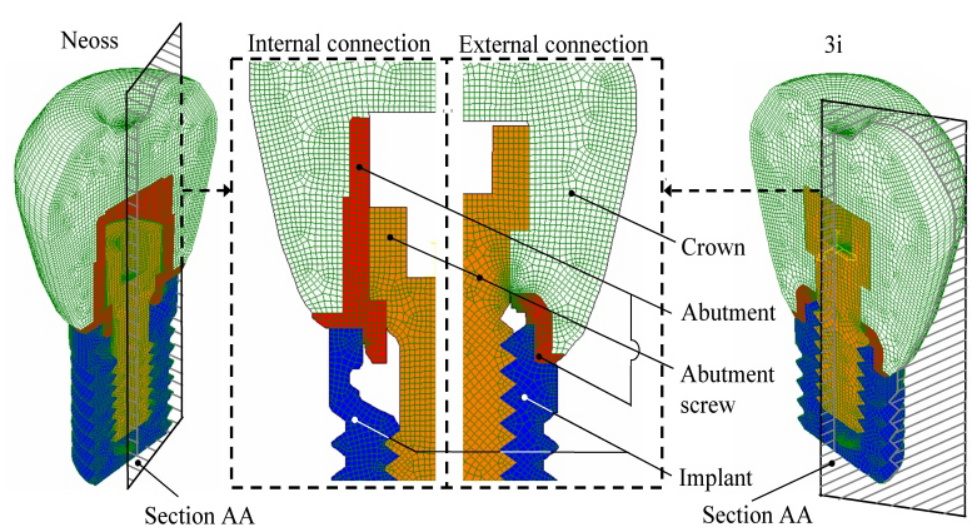

b) Implant systems internal and external-hex systems can be evaluated for their contributions to the stress characteristics within the crown.

\subsection{Modelling}

Data acquisition for the internal and external-hex systems are obtained from the manufacturer's data. Shown in Figure 1b) are details of the Neoss (2006) and $3 \mathrm{i}(2006)$ systems.

Shown in Figure 1a) are the detailed variables considered in this study. The implant is conical with 2 degrees of taperage, a helical thread, diameter of $4.5 \mathrm{~mm}$, and length of $11 \mathrm{~mm}$. Different fixed restraints are applied to the symmetrical edge of the implant system as compared to the outer edge of implant thread. The symmetrical edge is restrained from rotating around the $z$-axis and translating through the $x$ - and $y$-axis. The outer edge of the implant thread is restrained from deforming in any direction. Note that these loading and restraint conditions are the same for both internal and external-hex systems.

For the Neoss and $3 \mathrm{i}$ finite element models, the total numbers of elements are respectively 13464 and 30420 for the implant, 3564 and 9108 for the abutment, 17424 and 25956 for the abutment screw, 38484 and 47052 for the crown. The total number of nodal points for the entire Neoss and $3 \mathrm{i}$ models are 82547 and 122688 respectively.

\subsection{Stress Measuring}

As indicated in Figure 1c) the von Mises stresses along the lines $\mathrm{NN}\left(\mathrm{NN}_{1-2}, \mathrm{NN}_{2-3}\right.$ and $\left.\mathrm{NN}_{3-4}\right)$ and II $\left(\mathrm{II}_{1-2}, \mathrm{II}_{2-3}, \mathrm{II}_{3-4}, \mathrm{II}_{4-5}, \mathrm{II}_{5-6}\right.$ and $\left.\mathrm{II}_{6-7}\right)$ for the Neoss and $3 \mathrm{i}$ systems respectively, are measured for all possible combinations ofloading. Note that, for example, along the line $\mathrm{II}_{1-2}$ the beginning location of the line is identified as $\mathrm{II}_{1}$ and the end as $\mathrm{II}_{2}$. These locations are believed by clinicians to be critical for examining the stress levels in the crown. Note that both lines NN and II are chosen on Section AA because the highest stress magnitudes (compressive is prominent overten-

Figure 1. Finite element model of internal and external-hex systems.

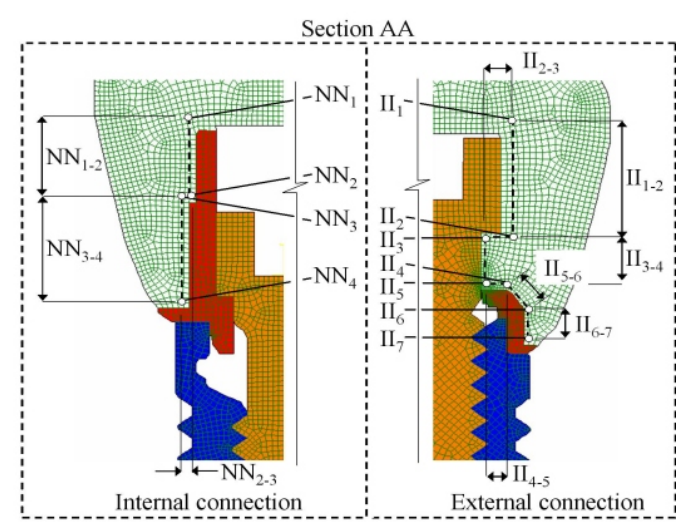

c) Locations for measuring stress profile and contour 
sile) occur on this plane due to the masticatory loading characteristics.

\subsection{Loading Conditions}

Masticatory force, $F_{M}$, is applied to the occlusal surface of the crown at 100,250 or $500 \mathrm{~N}$, inclined at $45^{\circ}$ along the $\mathrm{x}$ - and y-axis (Figure 1a). The preload, $F_{P}$, of $100.97,293.72$ or $504.84 \mathrm{~N}$ is applied to the abutment screw through the use of temperature sensitive elements (Figure 1a)). Note that $F_{M}$ and $F_{P}$ are set to half of the total magnitude because only half of the implant system is modelled. Therefore the total $F_{M}$ modelled is $200,500,1000 \mathrm{~N}$ and $F_{P}$ is $201.93,587.44$, $1009.67 \mathrm{~N}$. The manner of modelling the masticatory forces and the preload applied to the abutment screw is described by van Staden et al. (2008). In this study both the abutment screw preload, $F_{P}$, and surface area between abutment and abutment screw are halved when compared with that used by van Staden et al. (2008) due to the modelling assumption aforementioned. Calculations for the abutment screw surface pressure, $q$, confer identical results than that found by van Staden et al. (2008).

For the present study a negative temperature $(-10$ Kelvin, K) is applied to all the nodal points within the abutment screw, causing each element to shrink. A trial and error process is applied to determine the temperature coefficient, $C$, for both the Neoss and $3 \mathrm{i}$ systems (i.e. $C_{\text {Neoss }}$ and $C_{3 i}$ ) that can yield an equivalent

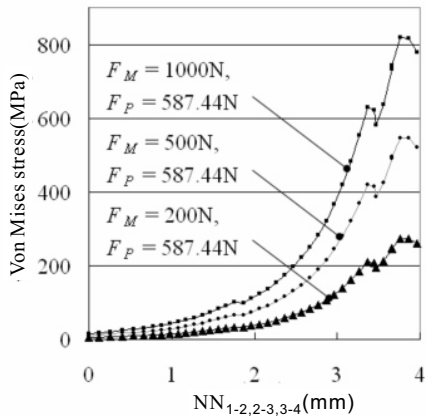

a) Stress profile

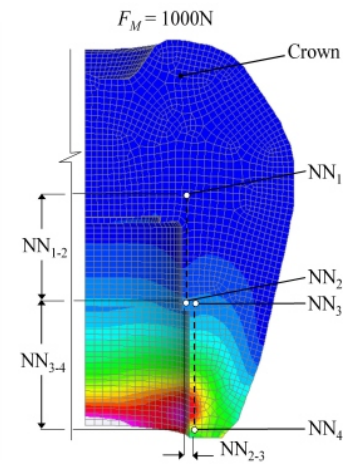

b) Stress contour

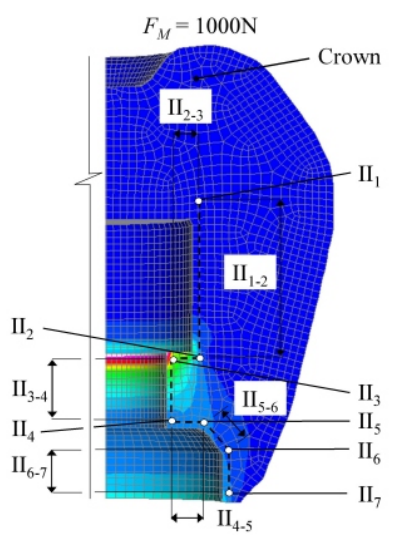

d) Stress contour
Table 1. Material propertles.

\begin{tabular}{lllll}
\hline Component & Description & $\begin{array}{l}\text { Young's mo- } \\
\text { dulus,E(Gpa) }\end{array}$ & $\begin{array}{l}\text { Poisons } \\
\text { ratio,v }\end{array}$ & $\begin{array}{l}\text { Density, } \\
(\mathrm{g} / \mathrm{cm} 3)\end{array}$ \\
\hline $\begin{array}{l}\text { Implantand } \\
\text { abutment }\end{array}$ & $\begin{array}{l}\text { Titanium } \\
\text { (grade4) }\end{array}$ & 105.00 & 0.37 & 4.51 \\
$\begin{array}{l}\text { Abutment } \\
\text { screw }\end{array}$ & $\begin{array}{l}\text { Gold(prec- } \\
\text { isionalloy) }\end{array}$ & 93.00 & 0.30 & 16.30 \\
Crown & $\begin{array}{l}\text { Zirconia(Y- } \\
\text { TZP) }\end{array}$ & 172.00 & 0.33 & 6.05 \\
\hline
\end{tabular}

$q$. It is found that when $F_{P}=201.93,587.44$ and $1009.67 \mathrm{~N}$ then $\mathrm{C}_{\text {Neoss }}=-3.51 \times 10^{-4},-9.28 \times 10^{-4}$ and $-15.60 \times 10^{-4} / \mathrm{K}$, and $\mathrm{C}_{3 i}=-0.98 \times 10^{-4},-1.80 \times 10^{-4}$ and $-2.68 \times 10^{-4} / \mathrm{K}$, respectively.

\subsection{Material Properties}

The material properties used are specified in terms of Young's modulus, Poisson's ratio and the density for the implant and all associated components (Table 1). All material properties are assumed to be linear, homogeneous and elastic in behavior.

\section{RESULTS DISCUSSION}

Zirconia typically used as a dielectric material has proven adequate for application in dentistry. With its typical white appearance and high Young's moduli it is ideal to be used in the manufacturing of sub frames
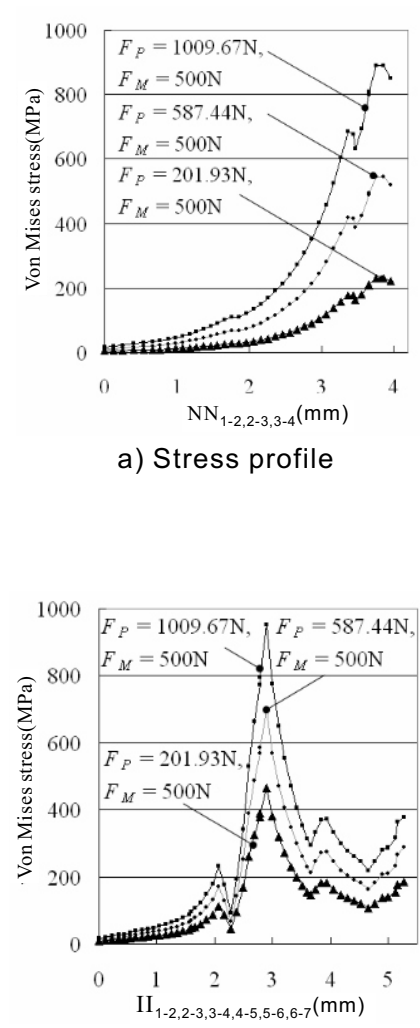

c) Stress profile a) Stress profile

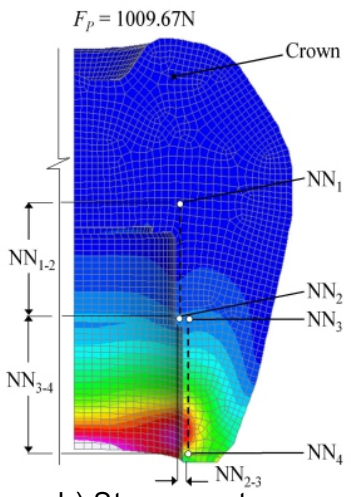

b) Stress contour

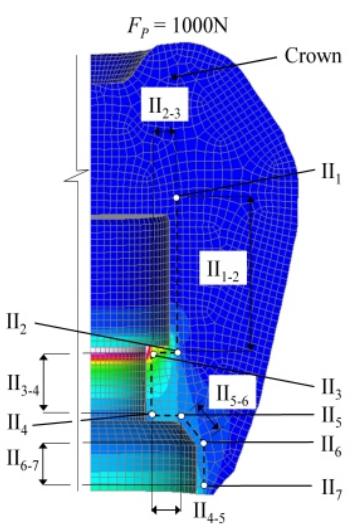

d) Stress contour
Figure 3. Stress characteristics when varying $F_{p}$.

Figure 2. Stress characteristics when varying $F_{M}$. 
for the construction of dental restorations such as crowns and bridges, which are then veneered with conventional feldspathic porcelain. Zirconia has a fracture strength that exceeds that of Titanium therefore it may be considered as a high strength material. However with cyclic preload and masticatory loads the compressive strength of $2.1 \mathrm{GPa}$ (Curtis et al. 2005) can easily be exceeded especially for implant systems with external-hex connections, as confirmed during this study.

The distribution of von Mises stresses in the crown is discussed for both the internal and external-hex systems for all combinations of masticatory and preload forces. Shown in Figure 1c), are the von Mises stresses measured between locations $\mathrm{NN}_{1-2}(0-$ $1.76 \mathrm{~mm}), \mathrm{NN}_{2-3}(1.76-1.87 \mathrm{~mm})$ and $\mathrm{NN}_{3-4}$ (1.87$3.96 \mathrm{~mm}$ ) for the Neoss system. For the $3 \mathrm{i}$ system the von Mises stresses are measured between locations $\mathrm{II}_{1-2}(0-2.38 \mathrm{~mm}), \mathrm{II}_{2-3}(2.38-2.78 \mathrm{~mm}), \mathrm{II}_{3-4}(2.78-$ $3.67 \mathrm{~mm}), \mathrm{II}_{4-5}(3.67-4.06 \mathrm{~mm}), \mathrm{II}_{5-6}(4.06-4.65 \mathrm{~mm})$ and $\mathrm{II}_{6-7}(4.65-5.27 \mathrm{~mm})$, as shown in Figure 1 c).

\subsection{Masticatory Force, $F_{M}$}

The distributions of von Mises stresses along the lines NN and II for all values of $F_{M}$ are shown in Figure 2. Note that the preload, $F_{p}$, is set at its medium value, i.e. $587.44 \mathrm{~N}$.

In general, when the applied masticatory force, $F_{M}$, is increased, the von Mises stresses also increase proportionally, because the system being analysed is linear elastic. When $F_{M}$ increases the stress along the line NN increases showing two peaks along the line $\mathrm{NN}_{3-4}$ (refer to Figure 2a)). The larger of these two peaks occurs at a distance of $\pm 3.8 \mathrm{~mm}$ in length from $\mathrm{NN}_{1}$. This stress peak (as can be identified in Figure 2b)) is caused by a sharp corner and sudden change in section at this point.

Elevated stress concentrations are identified at the beginning of the line $\mathrm{II}_{3-4}$ (Figure 2c) and Figure 2d)). This stress peak, as can beidentified in Figure 2c), is caused by a sharp corner at this point. For the $3 \mathrm{i}$ system, the volume of the crown exceeds that of the Neoss system, thereby suggesting that the $3 \mathrm{i}$ crown may endeavor greater resistance to the applied masticatory forces. However, even though the Neoss crown has a thinner wall thickness along the line $\mathrm{NN}_{3-4}$, reduced stresses are still evident due to the abutments high Young's modulus. Overall, the design differences between the Neoss and $3 \mathrm{i}$ systems ultimately results in the $3 \mathrm{i}$ system having higher stresses when $F_{M}$ is increased.

\subsection{Preload Force, $F_{P}$}

To investigate the effect of different preload $F_{P}, F_{M}$ is kept as a constant and its medium value, i.e. $500 \mathrm{~N}$ is considered herein. The distributions of von Mises stresses along the lines $\mathrm{NN}$ and II for all values of $F_{P}$ are shown in Figure 3.

As found for $F_{M}$, when $F_{P}$ increases the stresses calculated along the line $\mathrm{NN}$ increase, showing two peaks along the line $\mathrm{NN}_{3-4}$ (refer to Figure 3a) and Figure 3b)). Also, as found for $F_{M}$, elevated stress peaks are identified at the beginning of the line $\mathrm{II}_{3-4}$ (Figure 3c) and Figure 3d)). Overall, all values of $F_{M}$ cause greater stresses along lines NN and II, than do varying values of $F_{P}$.

\section{DISCUSSION}

FEA has been used extensively to predict the biomechanical performance of the jawbone surrounding a dental implant $[21,22]$. Previous research considered the influence of the implant dimensions and the bone-implant bond on the stress in the surrounding bone. However, to date no research has been conducted to evaluate the stress produced by different implant to crown connections (i.e. internal and external-hex). The analysis completed in this paper uses the FEM to replicate internal and external-hex systems when subjected to both $F_{M}$ and $F_{P}$ loading conditions. As shown in Table 2, two stress peaks were revealed along the lines NN and II at locations 3.76 and $2.89 \mathrm{~mm}$ from the top. The stress values shown were calculated with the other variables (i.e. $F_{M}$ or $F_{P}$ ) set to its average.

The mastication force $F_{M}$ is applied on the occlusal surface of the crown, evenly distributed along 378 nodal locations (Figure 1a), and orientated at $45^{\circ}$ in the $\mathrm{x}-\mathrm{y}$ plane. This induces compressive stresses in the right hand side of the crown and tensile in the left. Varying $F_{M}$ from 200 to $1000 \mathrm{~N}$ for the internal and external-hex systems results in a change in von Mises stress of 545.64 (818.47$272.82 \mathrm{MPa})$ and $698.09 \mathrm{MPa}(1047.14-349.05 \mathrm{MPa})$ respectively. The geometrical design of the externalhex system tends to induce stress concentrations, located $2.89 \mathrm{~mm}$ from the apex in this study. For this system, a stress concentration at this point is also induced by $F_{P}$, increasing the compressive stresses on the right hand side of the crown. Increasing $F_{P}$ from its minimum to maximum values, for the external-hex system, increases the stress by $485.46 \mathrm{MPa}$ (951.67-466.21MPa).

The internal-hex system has reduced stress concen-

Table 2. Von Mises stress (MPa) in crown (location of stress recording in brackets).

\begin{tabular}{|l|c|c|c|c|c|c|}
\hline \multirow{2}{*}{ Lariables } & \multicolumn{3}{|c|}{$F_{M}(\mathbf{N})$} & \multicolumn{3}{c|}{$F_{P}(\mathbf{N})$} \\
\cline { 2 - 7 } & 200 & 500 & 1000 & 201.93 & 587.44 & 1009.67 \\
\hline $\begin{array}{l}\text { NN } \\
(3.76 \mathrm{~mm})\end{array}$ & 272.82 & 545.64 & 818.47 & 231.55 & 545.64 & 891.83 \\
\hline $\begin{array}{l}\text { II } \\
(2.89 \mathrm{~mm})\end{array}$ & 349.05 & 698.09 & 1047.14 & 466.21 & 698.09 & 951.67 \\
\hline
\end{tabular}


trations, demonstrating that this design is less susceptible to stress concentrations within the crown. However, because of the transfer of the preload through the abutment screw to abutment contact, changing $F_{P}$ is more influential on this hex system than $F_{M}$. Overall $F_{M}$ is more influential on the stress within the crown for the external-hex system and $F_{P}$ is more influential on the internal-hex system.

\section{CONCLUSION}

This research is a pilot study aimed at offering an initial understanding of the stress distribution characteristics in the crown under different loading conditions. Realistic geometries, material properties, loading and support conditions for the implant system were considered in this study. The geometrical design of the external-hex system tends to induce stress concentrations in the crown at a distance of $2.89 \mathrm{~mm}$ from the apex. At this location, $F_{P}$ also affects the stresses, so that the compressive stresses on the right hand side of the crown are increased. The internal-hex system has reduced stress concentrations in the crown. However, because the preload is transferred through the abutment screw to the abutment contact, changing $F_{P}$ has greater effect on this hex system than $F_{M}$. Overall $F_{M}$ is more influential on the stress within the crown for the external-hex system and $F_{P}$ is more influential on the internal-hex system.

Future recommendations include the evaluation of other implant variables such as the implant wall thickness and thread design. Ultimately, all implant components can be understood in terms of their influence on the stress produced within the implant itself.

\section{ACKNOWLEDGEMENTS}

This work was made possible by the collaborative support from griffith's school of engineering and school of dentistry and oral health. Aspecial thank you goes to messer john divitini and fredrik engman from neoss pty ltd for their continual contribution.

\section{REFERENCE}

[1]Y. Maeda, T. Satoh \& M. Sogo. Invitro differences of stress concentrations for internal and external hex implantabutment connections: a short communication. Journal of Oral Rehabilitation 2006, 33:75-78.

[2]B. R. Merz, S. Hunenbart \& U. C. Belser. Mechanics of the implantabutment connection: an 8-degree taper compared to a butt joint connection. International Journal of Oral and Maxillofacial Implants 2000, 15:519-526.

[3]A. Khraisat, R. Stegaroiu, S. Nomura \& O. Miyakawa. Fatigue resistance of two implant/abutment joint designs. Journal of Prosthetic Dentistry 2002, 88:604-610.

[4]S. Capodiferro, G. Favia, M. Scivetti, G. De Frenza \& R. Grassi. Clinical management and microscopic characterisation of fatique-induced failure of a dental implant. Case report. Head and Face Medicine 2006, 22, 2:18.

[5]P. Gehrke, G. Dhom, J. Brunner, D. Wolf, M. Degidi \& A. Piattelli. Zirconium implant abutments: fracture strength and influence of cyclicloading on retaining-screw loosening. Quintessence International 2006, 37, 1:19-26.

[6]A. Khraisat. Stability of implant-abutment interface with a hexagon-mediated butt joint: failure mode and bending resistance.
Clinical Implant Dentistry and Related Research 2005, 7(4):221-228

[7]F. H. G. Butz, M. Okutan \& J. R. Strub. Survival rate, fracture strength and failure mode of ceramic implant abutments after chewing simulation. Journal of Oral Rehabilitation 2005, 32(11):838-843.

[8]K. J. Anusavice \& P. H. Dehoff. Influence of metal thickness on stress distribution in metal-ceramic crowns. Journal of Dental Research 1986, 65(9):1173-1178.

[9]K. J. Anusavice. Stress distribution in metal-ceramic crowns with a facial porcelain margin. Journal of Dental Research 1987, 66(9): 1493-1498.

$[10] \mathrm{K}$. J. Anusavice. Influence of incisal length of ceramic and loading orientation on stress distribution in ceramic crowns. Journal of Dental Research 1988, 67(11):1371-1375.

[11]H. Y. Suzuki. Finite element stress analysis of ceramics crown on premolar. Relation between ceramics materials and abutment materials. Nippon Hotetsu Shika Gakkai Zasshi 1989, 33(2):283-293.

[12]T. Hino. A mechanical study on new ceramic crowns and bridges for clinical use. Osaka Daigaku Shigaku Zasshi 1990, 35(1):240-267.

[13]Zhang, B. \& Wang, H. Three-dimensional finite element analysis of all-ceramic crowns of the posterior teeth. Hua Xi Yi Ke Da Xue Xue Bao 2000, 31(2):147-148.

[14]K. A. Proos, J. Ironside \& G. P. Steven. Finite element analysis studies of an all-ceramic crown on a first premolar. International Journal of Prosthodontics 2002, 15(4):404-412.

[15]A. Imanishi, T. Ohyama \& T. Nakamura. 3-D Finite element analysis of all-ceramic posterior crowns. Journal of Oral Rehabilitation 2003, 30(8):818-822.

[16] Strand7 Pty Ltd. Strand7 Theoretical Manual 2004. Sydney, Australia.

[17]Neoss Pty Ltd, Neoss Implant System Surgical Guidelines 2006. United Kingdom.

[18]http://www.3i-online.com.htm (accessed $12^{\text {th }}$ July 2006).

[19]R. C. van Staden, H. Guan, Y. C. Loo, N. W. Johnson \& N. Meredith. Stress Evaluation of Dental Implant Wall Thickness using Numerical Techniques.Applied Osseointegration Research 2008, (In Press).

[20]A. R. Curtis, A. J. Wright \& G. J. Fleming. The influence of simulated masticatory loading regimes on the bi-axial flexure strength and reliability of a Y-TZP dental ceramic. Journal of Dentistry 2005, 34(5):317-325.

[21]D. H. De Tolla, S. Andreana, A. Patra, R. Buhite \& B. Comella. Role of the finite element model in dental implants. Journal of Oral Implantology 2000, 26(2):77-81.

[22]J. P. Geng, K. B. Tan \& G. R. Liu. Application of finite element analysis in implant dentistry: a review of the literature. Journal of Prosthetic Dentistry 2001, 85(6):585-598. 